\title{
DIVERSIDADE DE PARASITAS EM QUIRÓPTEROS DO BIOMA AMAZÔNIA
}

\author{
PARASITES DIVERSITY IN BATS FROM AMAZON BIOME
}

\author{
A. C. A. de ALBUQUERQUE ${ }^{*}$, M. F. D. MORAES ${ }^{1}$, A. C. da SILVA ${ }^{1}$, J. H. TEBALDI ${ }^{1}$, \\ E. G. LUX HOPPE 1 .
}

\section{RESUMO $^{1}$}

A Amazônia é o maior Bioma brasileiro, com uma das maiores biodiversidades mundiais, sendo o Pará o segundo maior estado inserido neste Bioma. Dentre as 167 espécies de morcegos descritas no Brasil, 120 foram registradas no Estado do Pará. Apesar da diversidade, são raros os estudos voltados para a descrição de helmintos em quirópteros pertencentes a este Bioma. Diante disso, o presente estudo tem como objetivo estudar os helmintos presentes em diferentes espécies de quirópteros pertencentes ao Bioma Amazônia. Foram utilizados 67 espécimes de morcegos pertencentes às famílias Phyllostomidae, Molossidae, Vespertilionidae e Natalidae provenientes da região Amazônica, mais especificamente do Estado do Pará, obtidos em capturas realizadas pelas Secretarias Municipais de Saúde e Centros de Controle de Zoonoses do Estado do Pará (CCZ) e encaminhados ao Laboratório de Raiva do Instituto Evandro Chagas. Os parasitas obtidos foram identificados taxonomicamente segundo chaves taxonômicas e os indicadores de infecção helmíntica foram calculados. Foram coletados no total de 182 espécimes de parasitas, sendo os resultados apresentados em prevalência, intensidade média e abundância média, de cestódeos foram identificados: 01 espécime de Hymenolepididae $(1,49 \% ; 1,00 ; 0,01)$; de trematódeos: 61 espécimes de Anenterotrema eduardocaballeroi $(5,9 \% 7 ; 15,25 ; 0,91), 79$ de Anenterotrema liliputianum $(5,97 \% ; 19,75 ; 1,18), 34$ de Ochoterenatrema caballeroi $(4,48 \% ; 11,33 ; 0,51)$; e de nematódeos: 3 de Tricholeiperia sp. $(2,99 \% ; 1,50$; $0,04)$, Litomosoides brasiliensis $(1,49 \% ; 1,00 ; 0,01)$, Litomosoides guiterasi $(1,49 \% ; 1,00 ; 0,01)$, Capillarinae $(1,49 \% ; 1,00 ; 0,01)$, Parahistiostrongylus octacanthus $(1,49 \% ; 1,00 ; 0,01)$. Dentro as espécies de morcegos estudadas a Carollia perspicillata foi a que apresentou maior diversidade parasitária, com novos registros de helmintos para a espécie. A diversidade parasitária encontrada nos animais do presente estudo foi inferior à encontrada em estudos realizados no centro-oeste de São Paulo, contrapondo pesquisas que afirmam que animais pertencentes a regiões mais próximas a linha do equador possuem maior diversidade de espécie de parasitas.

PALAVRAS-CHAVE: Chiroptera, Helmintos, Ecologia.

AGRADECIMENTOS: Agradecimentos pelo auxílio financeiro do Conselho Nacional de Desenvolvimento Científico e Tecnológico $(C N P q)$.

ÁREA TEMÁTICA: Doenças Parasitárias

\footnotetext{
${ }^{1}$ Faculdade de Ciências Agrárias e Veterinárias da Universidade Estadual Paulista (UNESP) - Câmpus de Jaboticabal *e.hoppe@gmail.com
} 